\title{
UM ESPAÇO PARA REVITALIZAÇÃO: A TECNOLOGIA BIM NA PRESERVAÇÃO DA MEMÓRIA HISTÓRICA
}

\author{
DINIZ, PÂMELA J. G. A. \\ Estudante \\ IFPB - Princesa Isabel \\ Paraíba, Brasil \\ pamela.diniz@academico.ifpb.edu.br
}

\section{SOUSA, NÍLBERTE M.}

Professor

IFPB - Princesa Isabel

Paraíba; Brasil

nilberte.muniz@hotmail.com

\author{
ADVÍNCULA, CHYARA C. B. \\ Professor \\ IFPB - Princesa Isabel \\ Paraíba, Brasil \\ chyara.advincula@ifpb.edu.br
}

\author{
ANTAS, MARBSON G. \\ Estudante \\ IFPB - Princesa Isabel \\ Paraíba, Brasil \\ marbson.goulart@academico.ifpb.edu.br \\ SILVA, RINALDO R. \\ Professor \\ IFPB - Princesa Isabel \\ Paraíba, Brasil \\ rinaldo.rodopiano@academico.ifpb.edu.br
}

\author{
SOUZA, M. A. S. \\ Estudante \\ IFPB - Princesa Isabel \\ Paraíba, Brasil \\ maria.aline@academico.ifpb.edu.br
}

\begin{abstract}
RESUMO
O açougue municipal, localizado na cidade de Princesa Isabel - PB, datado de 1933, tem como modelo arquitetônico o estilo Art Déco, caracterizado pela presença de formas geométricas, surgido na Europa. E que foi negligenciada nas manutenções durante seu tempo de uso. Assim, o objetivo do trabalho foi de identificar as manifestações patológicas existentes na estrutura e propor a sua revitalização. Para tanto, foi utilizado a inspeção visual in loco para a identificação das patologias, feito o uso de paquímetros e trenas para medições, além da utilização da tecnologia BIM (Building Information Model) através do programa REVIT para modelar e documentar a proposta de restauração da edificação. Com isso, foi possível constatar a presença das manifestações patológicas existentes no imóvel, apresentar a virtualização em 3D da edificação, como também a percepção antecipada das possíveis interferências com o intuito de recuperar a construção sem a perda das suas características originais.
\end{abstract}

Palavras-chave: manifestações patológicas, revit, bim

\begin{abstract}
The municipal butcher shop, located in the city of Princesa Isabel - PB, dated 1933, has as its architectural model the Art Deco style, characterized by the presence of geometric shapes, emerged in Europe. And that was neglected in the maintenance during its use time. Thus, the objective of the work was to identify the pathological manifestations existing in the structure and propose their revitalization. In order to do so, visual on-site inspection was used to identify pathologies, using calipers and measuring tape, as well as the use of BIM (Building Information Model) technology through the REVIT program to model and document the restoration proposal. edification. Thus, it was possible to verify the presence of pathological manifestations in the property, present the $3 \mathrm{D}$ virtualization of the building, as well as the early perception of possible interference in order to recover the construction without losing its original characteristics.

Keywords: pathologic manifestations, bim, revit.
\end{abstract}




\section{INTRODUÇÃO}

A construção civil vem se desenvolvendo cada vez mais, e com isso surgem novas tecnologias com o intuito de contribuir no desenvolvimento e motivar as comunidades de Arquitetura, Engenharia, Construção e Gerenciamento de Instalações a gerenciar recursos de maneira eficiente. E devido aos longos ciclos de vida da construção, o gerenciamento de manutenção também é uma alavanca importante para lidar com a eficiência de recursos (VOLK; STENGEL; SCHULTMANN, 2014).

Nesse contexto, o BIM (Building Information Modeling) é uma metodologia poderosa, introduzida com grande sucesso no domínio da Arquitetura, Engenharia e Construção. A indústria da construção tem trabalhado intensamente na implementação da metodologia BIM em vários segmentos. Essa tecnologia é um conceito de trabalho colaborativo, fortemente baseado em avanços tecnológicos em computação. As ferramentas BIM permitem o desenvolvimento de projetos de construção durante seu ciclo de vida, incluindo as fases de design, construção, manutenção, gerenciamento e demolição (NEVES; SAMPAIO; VILELA, 2019).

Tendo como foco a manutenção e/ou reforma, o modelo BIM arquitetônico deve responder a três perguntas principais: "o quê", "por que" e "como" cada parte a ser renovada foi construída. Por esse motivo, cada tipo de construção é necessário escolher um "nível de desenvolvimento" e um "nível de precisão" das informações, relacionados ao tipo de intervenção e o mais homogêneo possível, a fim de obter um modelo fácil para gerenciar e entender. A tecnologia BIM permite a simulação de diferentes tipos de intervenção, ajudando o projetista a escolher a solução mais eficiente (BIAGINI et. al., 2016).

De acordo com Styliadis (2008), existem muitas razões e motivos para modelar em 3D objetos, edifícios e cenas do mundo real, incluindo: reconstrução virtual de edifícios e monumentos históricos, entre elas a capacidade de interação virtual sem o risco de danos; produção de dados para recursos educacionais; turismo virtual e exposições em museus virtuais.

Em geral, a maioria dessas aplicações específica dez requisitos: alta precisão geométrica; ambiente de interação amigável; todos os detalhes capturados; fotorrealismo de qualidade; vídeo virtual; alta automação e baixa interação do usuário; portabilidade; baixo custo; eficiência do tamanho do modelo e flexibilidade da aplicação. A ordem de importância desses requisitos depende do objetivo do aplicativo. Portanto, para aplicações de documentação digital, a precisão geométrica e a captura de todos os detalhes estão no topo desses requisitos, enquanto que para o e-turismo e a e-cultura devem ser tomados cuidados especiais com o fotorrealismo virtual de vídeo e de qualidade (STYLIADIS, 2008).

Assim, o objetivo deste trabalho foi de identificar as manifestações patológicas existentes na estrutura e propor a sua revitalização, além de desenvolver a documentação digital da edificação histórica. Com o intuito de preservar o patrimònio material que faz parte das memórias de uma região.

\section{2. ÁREA DE ESTUDO}

Após a Revolução de 1930 e a ascensão de Getúlio Vargas, a cidade de Princesa Isabel muda de prefeito por indicação de José Américo. A nível nacional Vargas objetivava a centralização e modernização da administração pública, assim como fizeram o presidente do Estado da Paraíba João Pessoa em 1928 quando foi eleito para governar o Estado. Para tal intento, construíram mecanismos de controle e intervenção na economia e em outros setores do Estado, tais quais: saúde, instrução pública, justiça, etc.. O Estado se fez mais presente. Por isso, constata-se várias ações do poder público na administração, no meio social e urbano. Nesse ambiente de modernização, as cidades passaram a ser esquadrinhadas com base no discurso higienista. Para tanto, vários locais de controle foram organizados no espaço citadino.

Um desses espaços foi o açougue público. Local de venda de carne verde à varejo. A fiscalização tornou-se a ordem do dia para os reformadores. As cidades deveriam seguir os novos preceitos de saúde e higiene, e os os açougues não poderiam ficar de fora desse discurso. Sendo assim, a construção desses locais visava ser arejados e limpo (Bosi,2014). $\mathrm{Na}$ busca pelo moderno, a edificação procurava estar antenada com os modelos arquitetônicos em voga naquele momento. Desse modo, observamos que o açougue de Princesa, datado de 1933, segue o estilo da arte Déco, o qual tinha como uma de suas características o uso de formas geométricas, que são visíveis até os dias atuais. 


\section{METODOLOGIA}

A metodologia deste trabalho constituiu-se de uma inspeção in loco com o intuito de realizar o levantamento das manifestações patológicas presentes na edificação, propor sua restauração e realizar a documentação digital de sua fachada. Para tanto foram utilizados registros fotográficos, equipamentos de medições e uma ferramenta BIM que possibilitasse a realização de projetos.

\subsection{FERRAMENTA BIM UTILIZADA}

O programa utilizado no estudo foi o software Revit versão 2020, produzido pela empresa Autodesk, que utiliza a tecnologia BIM (Building Information Modeling ou Modelagem da Informação da Construção).

O BIM é uma tecnologia desenvolvida para que houvesse a integração de informações que compõe uma obra, desde seu planejamento à sua demolição, saindo dos padrões de $2 \mathrm{D}$ e alcançando outras dimensões. A metodologia dessa tecnologia representa toda a geometria do projeto em conjunto com suas características, como as informações funcionais da obra, agora, em um único trabalho. Essa integração entre os processos de uma obra e a agilidade de leitura que os softwares proporcionam, geram melhor administração do tempo e, consequentemente, o aumento da trabalhabilidade na execução.

A utilização do software Revit permitiu que fosse possível inserir um registro fotográfico ortogonal, da fachada do açougue (Figura 1), que possibilitou gerar o redimensionamento da imagem através de um escalonamento utilizando linhas de detalhe. Com a dimensão da construção aferida, in loco, foram utilizados dois pontos da imagem sem escala alinhados com dois pontos da linha de detalhe em escala com a medida linear real da edificação. Com base no resultado gerado pelo escalonamento, a modelagem da edificação foi sendo projetada utilizando ferramentas de modelagem de extrusão do programa, os detalhes de sobreposição foram desenhados e o modelo da fachada do edifício gerado já na vista 3D (Figura 2).

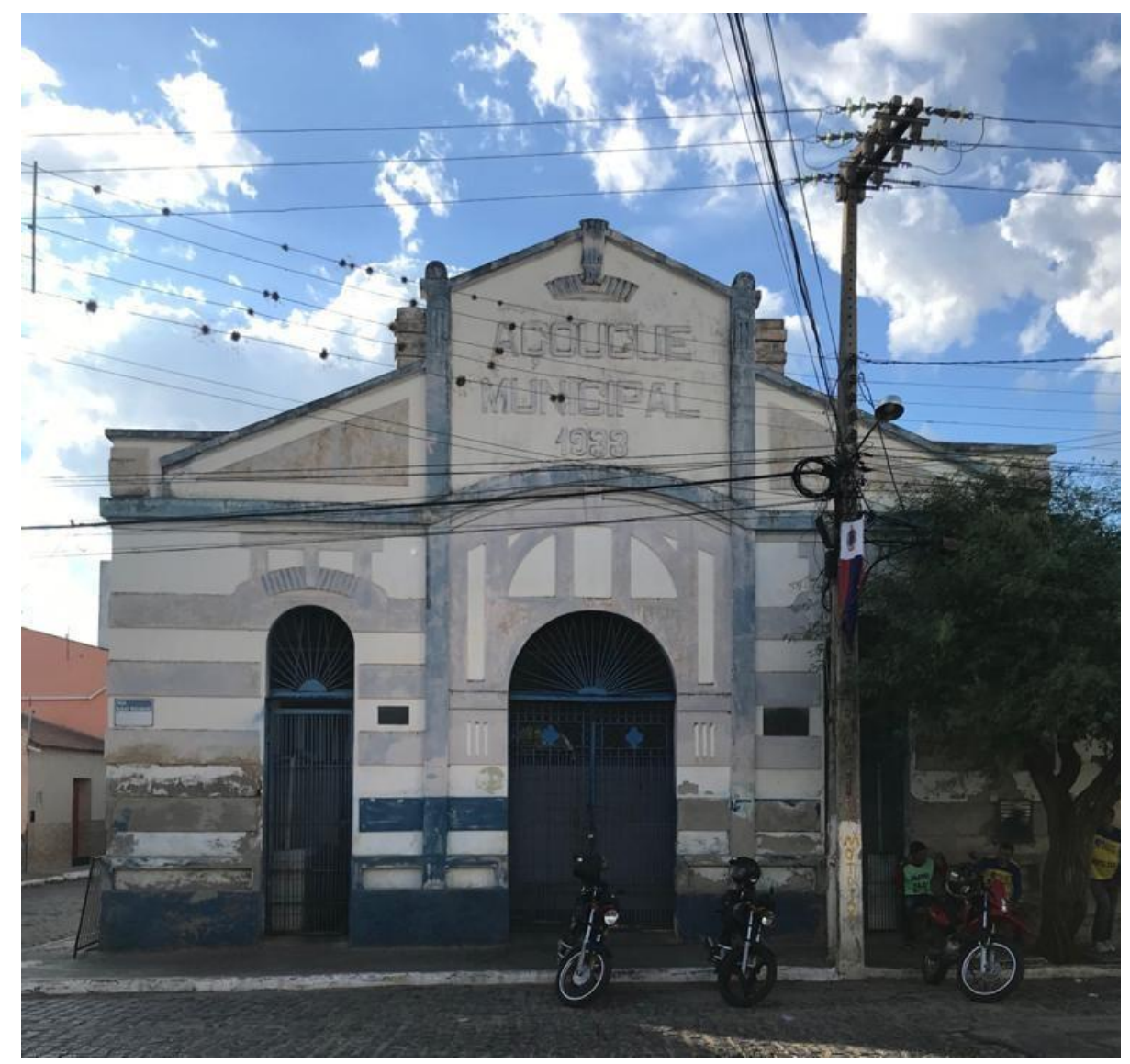

Figura 1 - Foto da fachada do Açougue 


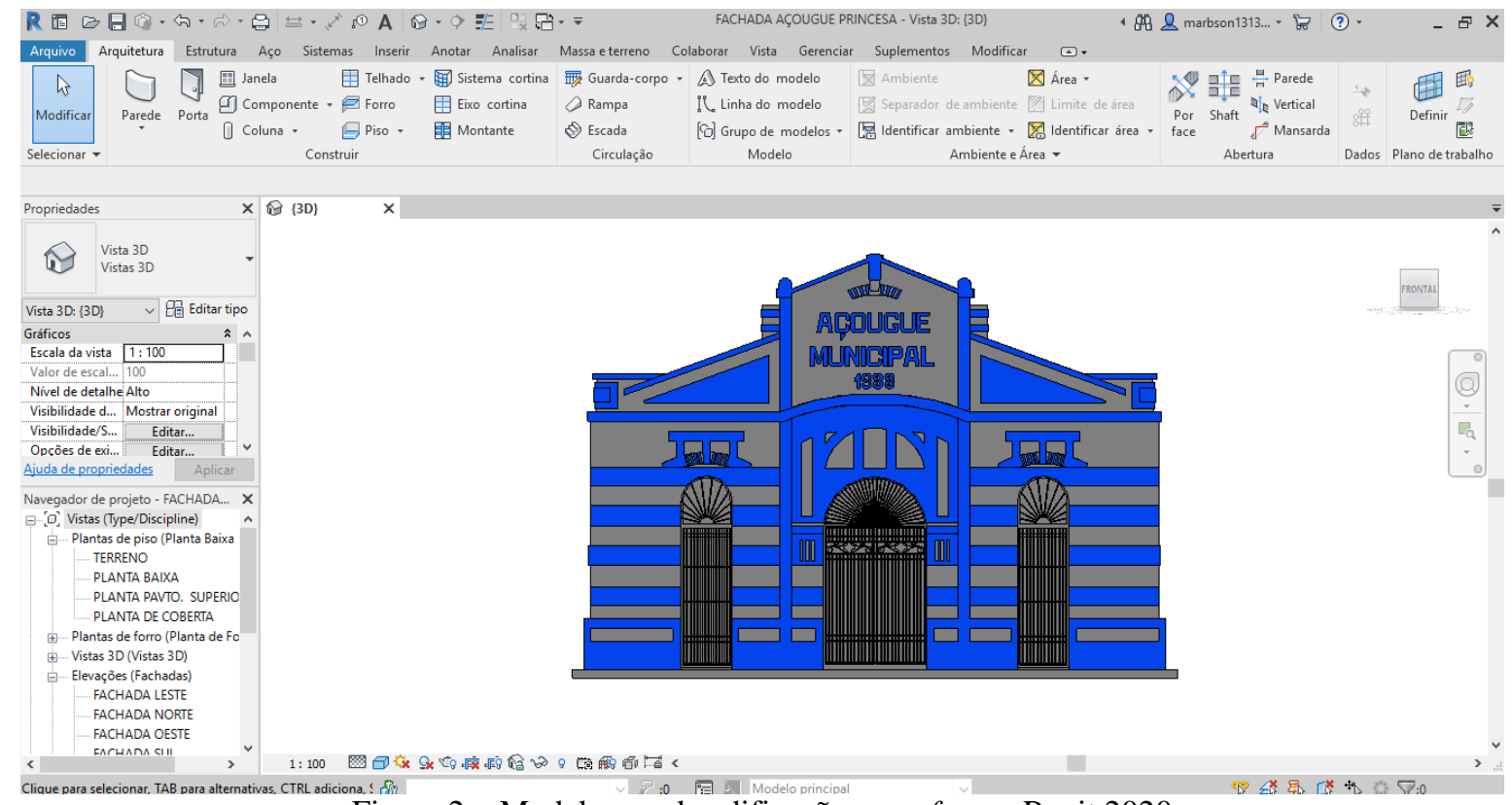

Figura 2 - Modelagem da edificação no software Revit 2020

\section{INSPEÇÃO E IDENTIFICAÇÃO DAS MANIFESTAÇÕES PATOLÓGICAS}

Durante as inspeções in loco, foi observado que a parte interna da edificação encontra-se reformada, com o intuito de atender as exigências necessárias para a utilização do açougue. Entretanto, a sua área externa foi negligenciada e apresenta diversos problemas, tais como destacamento da pintura, degradação da argamassa, bolor e aplicação de reboco inadequada.

Na figura 3 é possível perceber o destacamento da pintura, tendo como possíveis causas a umidade, que faz com que surjam fissuras nas pinturas, ou até mesmo, por se tratar de uma edificação pública, a falta de um controle de qualidade das tintas utilizadas possibilita uma redução da vida útil desse tipo de acabamento.

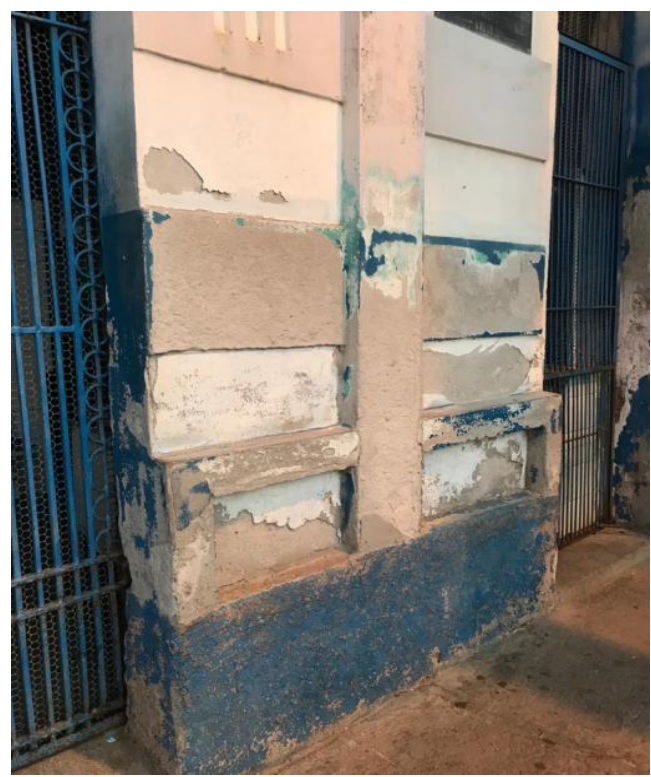

Figura 3 - Destacamento da pintura 


\section{CBPAT 2020 \\ CONGRESSO BRASILEIRO DE PATOLOGIA DAS CONSTRUÇÕES DE 15 A 17 DE ABRIL | FORTALEZA - CE

Já a degradação da argamassa (Figura 4), que tem como características a pulverização do reboco, que afeta diretamente a pintura da edificação, uma vez que argamassa que serve de base para esse tipo de acabamento apresenta desagregação e esfarelamento, deixando o substrato exposto a intempéries. A provável causa desse tipo de patologia é a criptoflorescência que surge entre a superfície externa e a camada de pintura, aliada aos intemperismo que essas alvenarias estão suscetíveis.

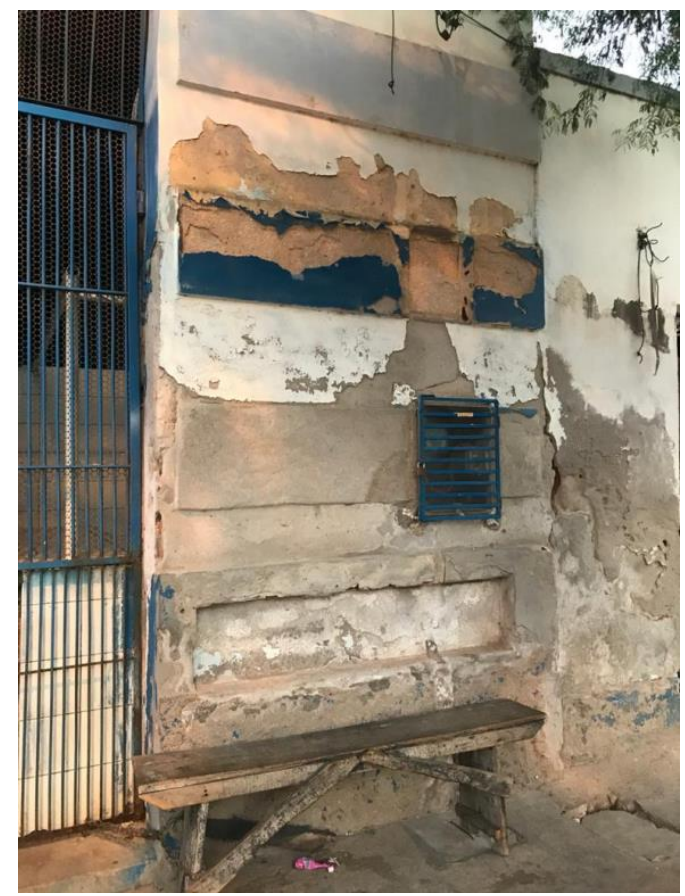

Figura 4 - Degradação da argamassa

Na Figura 5 observa-se a presença de bolor, que está relacionada à existência de umidade e a alteração na superfície de diferentes materiais, sendo consequência do desenvolvimento de microorganismos. Esses organismos possuem seus desenvolvimentos afetados com as condições ambientais. Na mesma figura, nota-se aplicação do reboco de maneira errônea, deixando o substrato exposto a intempéries, contribuindo para a infiltração.

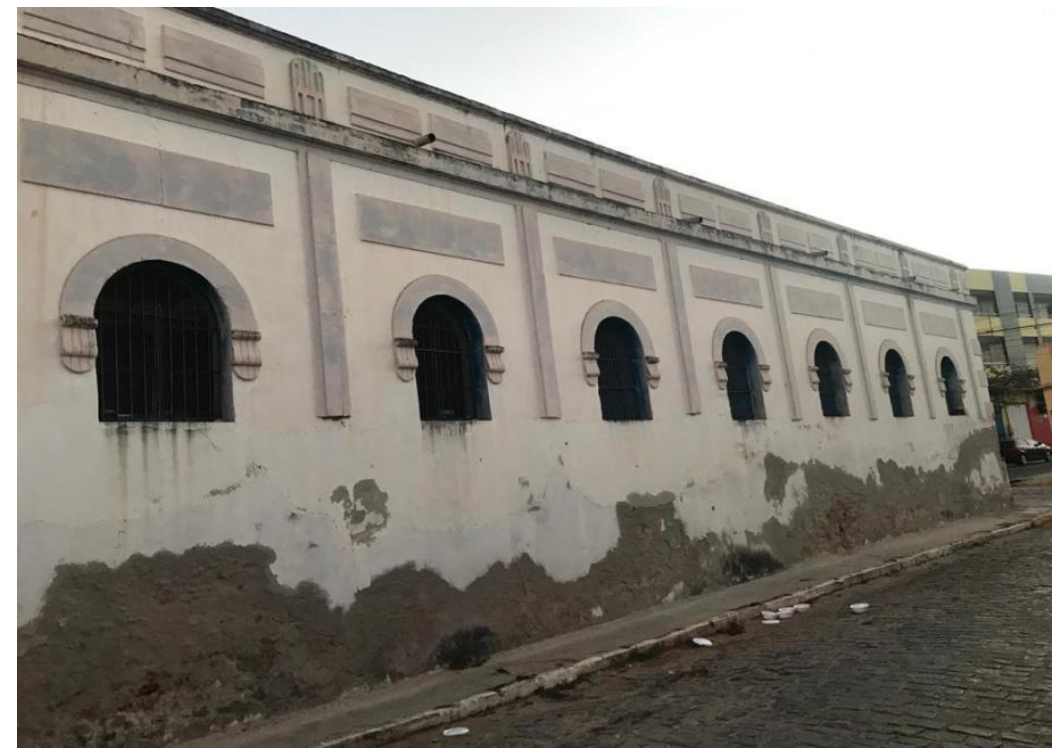

Figura 5 - Bolores e aplicação de reboco de maneira errada 


\section{PROPOSTA DE RESTAURAÇÃO E DOCUMENTAÇÃO DIGITAL}

A identificação das manifestações patologicas nas edificações é de fundamental importancia, principalmente quando se trata de um patrimonio historico. Isso possibilita que sejam feitas as intervenções nescesarias e garantir a preservação do patrimonio.

Com as manifestações patológicas detectadas, foi possível sugerir aos responsáveis pela preservação de patrimônios históricos os procedimentos nescessários para sua manutenção. Juntamente com a entrega da documentação digital, que proporciona o arquivamento da edificação, com todas as suas medidas e características, para que, sempre que necessário, possa realizar as devidas interferências na estrutura ou, até mesmo, se caso a edificação for danificada de alguma forma, possam restaurá-la com todas as suas particularidades. Assim, na Figura 6 observa-se a documentação digital da fachada frontal.

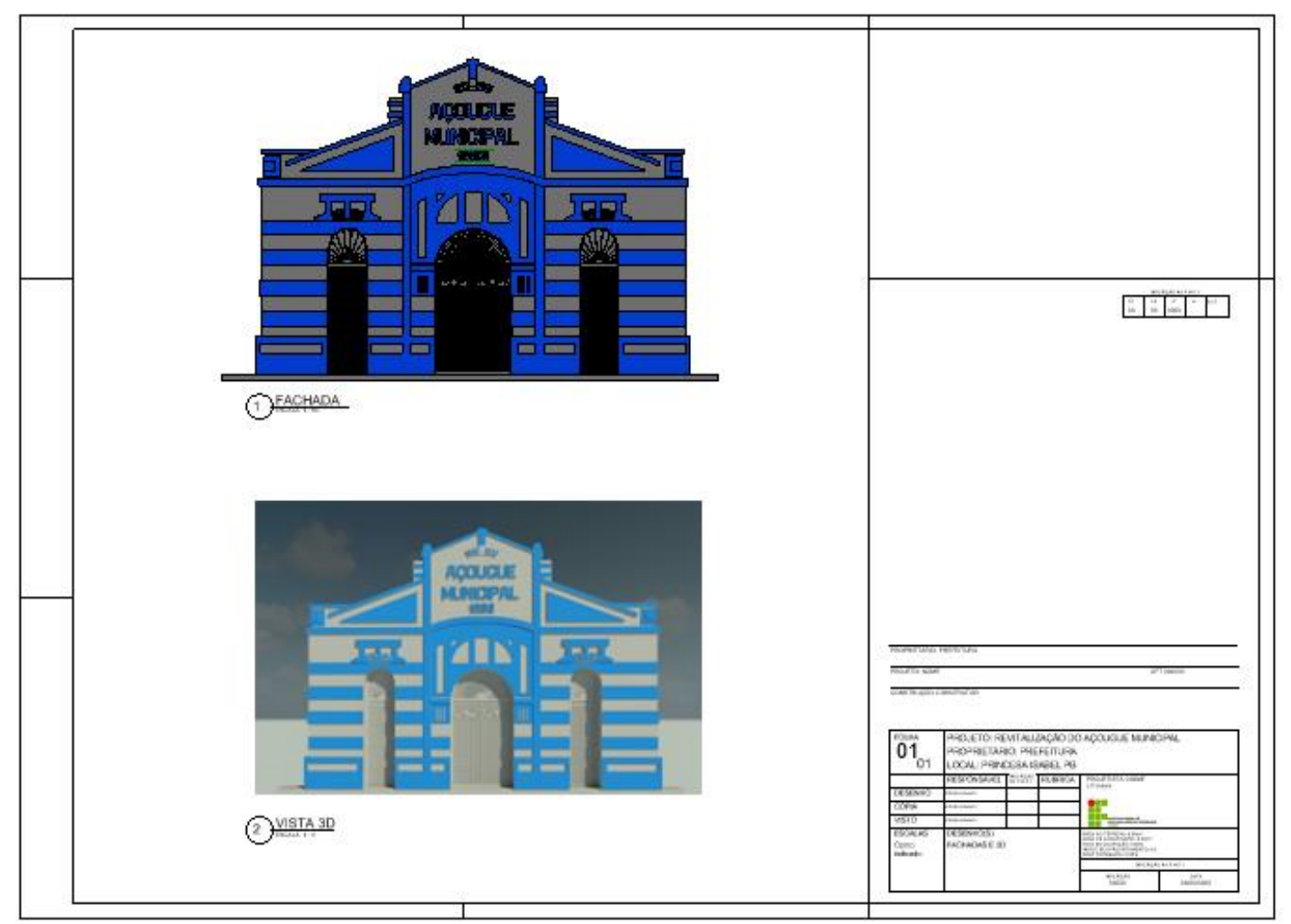

Figura 6: Documentação digital da fachada frontal

\section{CONCLUSÃO:}

É de fácil percepção o descaso do poder público pela preservação do patrimônio histórico. Assim, as avaliações das patologias são de grande importância para identificar o estado em que se encontra a edificação e a melhor maneira de restaurar-la sem que ela perca as particularidades de um patrimônio histórico.

No caso do açougue público, foi constatado que ouve uma reforma na parte interna da edificação, para que a mesma atingisse os requisitos de higiene necessários para seu mantimento. Porém, toda a parte externa foi extremamente negligenciada, sendo possível observar a presença de diversas patologias.

A documentação digital é de extrema importância no meio arquitetônico, principalmente quando o assunto é preservação do patrimônio histórico. Com isso, realizar a documentação do Açougue Municipal faz-se muito importante, tanto para registro na prefeitura de Princesa Isabel PB quanto para auxiliar na revitalização do edifício. Como não existe documentação no setor de infraestrutura da prefeitura municipal, é válido realizar, em outro momento, o levantamento métrico completo da edificação, colaborando, dessa forma, com o patrimônio histórico e público da cidade. 


\section{REFERÊNCIAS}

VOLK, R.; STENGEL, J.; SCHULTMANN, F. Building Information Modeling (BIM) for existing buildings Literature review and future needs. Automation in Construction. Volume 38, March 2014, Pages 109-127.

NEVES, J.; SAMPAIO, Z.; VILELA, M. A Case Study of BIM Implementation in Rail Track Rehabilitation. Infrastructures. V.4, 2019, p.1-13.

BIAGINI, C.; CAPONE, P.; DONATO, V.; FACCHINI, N. Towards the BIM implementation for historical building restoration sites. Automation in Construction. Volume 71, 2016, Pages 74-86.

STYLIADIS, A. D. Historical photography-based computer-aided architectural design: Demolished buildings information modeling with reverse engineering functionality. Automation in Construction. Volume 18, Issue 1, 2008, Pages 51-69.

BARBOSA, Maria Teresa Gomes; POLISSENI, Antônio Eduardo; TAVARES, Fabiana Mendes. Análise e representação em contextos diversos: projeto, técnica e gestão do ambiente construído: Patologias de Edifícios Históricos Tombados. 2010, p.3-6 